\title{
Assessment of a Battery Charger for Electric Vehicles with Reactive Power Control
}

\author{
Vítor Monteiro, J. G. Pinto, Bruno Exposto, Henrique Gonçalves, João C. Ferreira, Carlos Couto, João L. Afonso \\ Centro Algoritmi - University of Minho - Guimarães, Portugal \\ E-mails: \{vitor.monteiro, gabriel.pinto, bruno.exposto, henrique.goncalves, joao.ferreira, \\ carlos.couto, joao.l.afonso\}@algoritmi.uminho.pt
}

\begin{abstract}
Batteries of Electric Vehicles (EVs) and Plug-in Hybrid Electric Vehicles (PHEVs) have a large potential not only to provide energy for the locomotion of these vehicles, but also to interact, in dynamic way, with the power grid. Thereby, through the energy stored in the batteries, these vehicles can be used to regulate the active and the reactive power, as local Energy Storage Systems. This way, EVs can contribute to help the power grid to regulate the active and reactive power flow in order to stabilize the production and consumption of energy. For this propose should be defined usage profiles, controlled by a collaborative broker, taking into account the requirements of the power grid and the conveniences of the vehicle user. Besides, the interface between the power grid and the EVs, instead of using typical power converters that only work on unidirectional mode, need to use bidirectional power converters to charge the batteries (G2V - Grid-to-Vehicle mode) and to deliver part of the stored energy in the batteries back to the power grid (V2G Vehicle-to-Grid mode). With the bidirectional power converter topology presented in this paper, the consumed current is sinusoidal and it is possible to regulate the power factor to control the reactive power, aiming to contribute to mitigate power quality problems in the power grid. To assess the behavior of the presented bidirectional power converter under different scenarios, are presented some computer simulations and experimental results obtained with a prototype that was developed to be integrated in an Electric Vehicle.
\end{abstract}

\section{INTRODUCTION}

Nowadays, the recent and massive investments in electric mobility, mainly in Electric Vehicles (EVs) and Plug-in Hybrid Electric Vehicles (PHEVs), represents a new paradigm in the transports sector, alternatively to the vehicles with Internal Combustion Engines (ICE). For simplicity, from now on in this paper, it will be used the terminology Electric Vehicle (EV) both for EVs and PHEVs.

The proliferation of EVs will contribute do reduce the strong dependence from oil and other fossil fuels, allowing an effective reduction in the emissions of greenhouse gases. This way the impact of the transports sector in the climate change will be reduced. Nevertheless, for the electrical power grids EVs will be extra loads, which will consume energy to charge their batteries, and in many cases at the same time, and connected to the same distribution transformer.

With the electric mobility increase, taking into account the stored energy in the batteries of EVs, arises a new concept in the electrical power grid market denominated Vehicle-to-Grid (V2G) [1][2][3]. In this sense, besides the battery charging mode, denominated as Grid-to-Vehicle (G2V), the owners of these vehicles and the power grid can interact, through a collaborative broker, to negotiate the energy stored in the batteries, respecting a schedule to charge the batteries and the total time required [4]. The integration of EVs in the power grid distribution network, respecting the technical restrictions of the system, requires data analysis of the electrical consumption to allow the smart utilization of the batteries, where the charging $(\mathrm{G} 2 \mathrm{~V})$ or discharging (V2G) processes have to be coordinated with the users of the vehicles [5].

Focusing the integration of EVs in the power grid, in order to implement the V2G concept, it is necessary the use of bidirectional power converters. These converters, should be designed to allow the bidirectional flow of energy (with different control algorithms based on different stages of voltages and currents), and the current in the AC side should be sinusoidal with variable and controlled power factor. With these characteristics, it is preserved the lifetime of the batteries and the power quality of the electrical power grid. In this context, in [6][7] it is analyzed the impact of the battery chargers of EVs on the power quality, and it is proposed a tool that can be easily applied to determine the optimum charging time as function of the existing available power in the electrical power grid, the schedule and the ambient temperature.

Relatively to the power converters of the battery chargers, which typically consist in AC-DC and DC-DC converters, there are several topologies presented in the literature. In [8] are compared the basic topologies for power factor correction (PFC), using the DC-DC converters buck, boost, buck-boost, flyback, forward, cuk, sepic, and zeta, highlighting the operation of the DC-DC converters in discontinuous mode. In [9] is presented a comprehensive review of various techniques to PFC with their control systems, advantages and disadvantages. In [10] is proposed a new low-stress buckboost converter for universal input PFC applications, and is made a comparison with the boost converter. Circuit topologies for PWM boost rectifiers are presented in [11]. Due to the unidirectional mode of operation, these converters are not suitable for V2G applications. For this purpose should be used topologies with bidirectional operation [12][13]. In [14] are presented basic requirements and specifications for the bidirectional converters of EVs.

Independently of the power converter topology, the battery chargers can be categorized as on-board or off-board. The onboard battery chargers are placed inside the vehicles, and typically are designed to allow charging the batteries in slow mode using standard plugs and sockets in the connection to the power grid, as in homes or public workspaces. On the 
other hand, the off-board battery chargers are placed outside of the vehicle, due to the volume and weight, and are designed to allow the charge of the batteries in a short time.

In this paper is presented and analyzed the development of a bidirectional power converter to charge the batteries through the concept Grid-to-Vehicle (G2V), and to deliver back to the power grid a small amount of the stored energy in the batteries, according to the power grid requirements and with the user agreement, through the concept Vehicle-to-Grid (V2G). The bidirectional power converter was designed to preserve the power quality of the electrical power grid through sinusoidal current consumption, with controlled power factor, allowing the control of the active and reactive power [2]. It also was designed to allow charging the batteries with different modes, based on different voltages and currents levels, aiming to preserve the batteries lifetime.

In order to validate the different modes of operation, in a first stage the bidirectional power converter topology and the control algorithms were validated by computer simulations, and then were validated through experimental results with the developed prototype.

\section{SMART GRID: ELECTRIC MOBILITY INTEGRATION}

With the electric mobility integration, it is predictable that in the near future, in a real full scale Smart Grid scenario, the power grid should meet the increasing demand of energy in a reliable and efficient way, maintaining the required stability. At the same time it should allow the interface of renewable energy resources with their intermittent production. The integration of EVs in the power grid is approached in several papers in the literature [15][16][17]. In [18] is analyzed the impact of the EVs in the power grid, but for isolated systems.

\section{A. Energy Storage Systems}

With Energy Storage Systems (ESS), such as chemical batteries, flywheels or compressed air tanks, it is possible to maintain the stability of the power grid, mainly, to improve the use of renewable energy sources (it is possible to store the energy produced when the demand is low in order to be used later when the demand increases) [19].

In this scenario, with the electric mobility integration and taking into account EVs equipped with bidirectional battery chargers, it will be possible the communication of these vehicles with local utilities to ensure that the batteries are charged when the impact on the grid is small. Also it will be possible to return part of the stored energy in the batteries back to the power grid. This way, these vehicles can operate as local ESS controlled by a collaborative broker.

Since in average most of the vehicles, are parked for long time periods, their batteries can be used as ESS, receiving energy during the excess of production and delivering energy back to the electrical grid during the periods of great demand, balancing the energy production and consumption. In this context, these vehicles are also useful to stabilize the intermittent production from renewables, improving their integration into the power grid.
In Fig. 1 is shown the integration of EVs in a typical charging park operating as ESS, and the integration of renewables in microgeneration (solar photovoltaic panels and micro wind turbines).

\section{B. Collaboration Modes}

EVs can collaborate with the power grid in several modes. The simplest process, denominated Grid-to-Vehicle (G2V), allows the flow of energy from the power grid to the vehicles, which consists in the common procedure of charging the batteries of the EVs.

The concept Vehicle-to-Grid (V2G) allows bidirectional flow of energy between EVs and the power grid. The MidAtlantic Grid Interactive Cars Consortium (MAGICC) defines V2G as a technology that utilizes the stored energy in the EV batteries to contribute with electricity back to the grid when the grid operators request it [20]. The operation of EVs as ESS requires the use of bidirectional flow of energy. Thus, besides the bidirectional control of the active power, it is also possible to control the reactive power in order to improve the operation of the electrical power grid.

The concept Vehicle-to-Home (V2H) allows the bidirectional flow of energy between the vehicle and the house, minimizing the energy transmission losses and the cost. In this way, it is possible to manage and regulate the profile of electricity demand in the house, controlling the use of the loads and the stored energy available in the batteries of the vehicle.

The concept Vehicle-to-Building (V2B) is similar to the $\mathrm{V} 2 \mathrm{G}$ concept, and it allows the use of the energy stored in the batteries of EVs as energy back-up system (ESS) and to compensate the energy consumption profile in commercial scale, e.g., when the vehicle is parked at the work or in a shopping center.

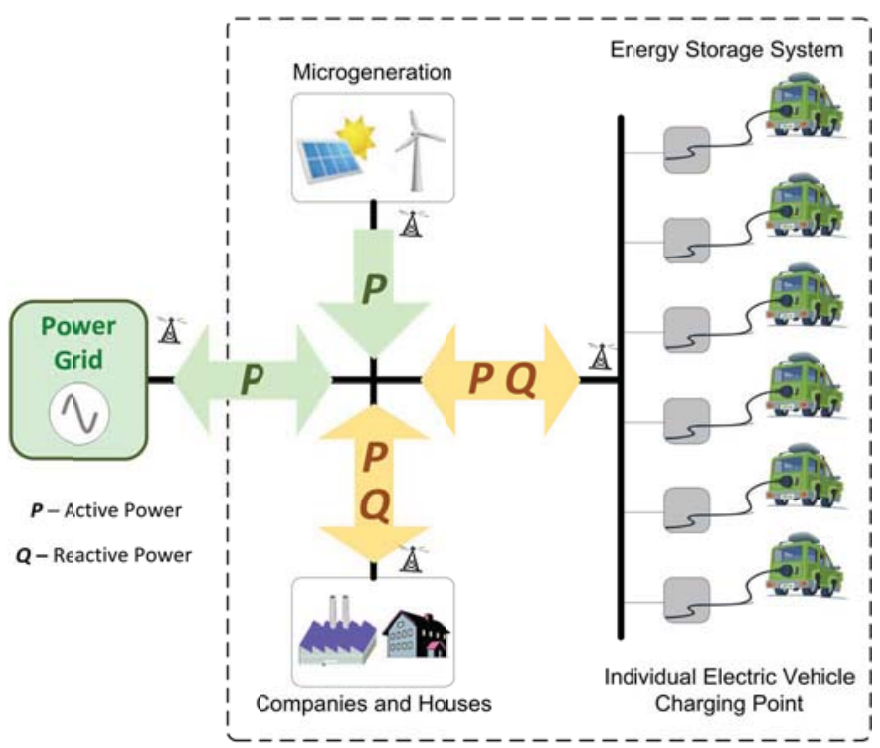

Fig. 1. Isolated system in Smart Grid context with power flow considering the integration of EVs (as Energy Storage Systems) and renewables. 


\section{Power Quality}

Taking into account the electric mobility integration, the main problems associated with power quality [21] are: voltage and current harmonics; low power factor; noise (electromagnetic interference); and unbalances. As a way to solve these problems can be used shunt active power filters (used to solve problems related with the current), series active power filters (used to solve problems related with the voltage), and unified power quality conditioners (used to solve problems related with current and voltages) [22][23].

However, with the topology of bidirectional converter for battery charger presented in this paper, the current in the $\mathrm{AC}$ electrical power grid side will be sinusoidal (this way it will not contribute to degrade the line current and voltage), and it will be possible to control the power factor. In [24] is analyzed a particular case of the impact of Plug-in Hybrid Electric Vehicles (PHEVs) in the electric utility system, where, basically it is approached the consumption profile and how these vehicles will affect the utility operation by adding additional electricity demand.

\section{BATTERY CHARGERS ANALYSIS}

In EVs the battery chargers are composed by power converters, which allow transform the AC power grid voltage, into $\mathrm{DC}$ voltage to charge the batteries.

The bidirectional power converter for EVs presented in this paper is composed by two power converters, one AC-DC and the other DC-DC. In Fig. 2 is shown the schematic of the proposed converter. Due to the topology of the bidirectional power converter, simultaneously with the charging of the batteries with the proper control algorithms, it is possible to consume sinusoidal current with controlled power factor. Thereby, besides controlling the active power it is also possible to control the reactive power. In Fig. 3 is shown the flow of active and reactive power involved in the interaction of this bidirectional power converter with the power grid. In Tab. I are summarized the different profiles of power consumption, considering inductive and capacitive power factor with different values. These different profiles of power consumption are configurable through the control system.

Taking into account that the power grid voltage is given by (1), the reference to the sinusoidal current with variable power factor is given by (2), where $k_{2}$ and $k_{3}$ are the amplitude of the references of the current, respectively.

The active power is adjusted taking into account the voltage and the current in the batteries, and the reactive power is adjusted according to the information provided by the collaborative broker concerning the current limits of the bidirectional power converter.

$$
\begin{gathered}
\mathrm{v}_{\text {grid }}=\mathrm{k}_{1} \cdot \sin (\omega \mathrm{t}) \\
\mathrm{i}_{\text {ref }}=\mathrm{k}_{2} \cdot \sin (\omega \mathrm{t})+\mathrm{k}_{3} \cdot \cos (\omega \mathrm{t})
\end{gathered}
$$

In a first stage to analyze the behavior of the bidirectional battery charger was performed several simulations with the simulation tool PSIM 9.1. In Fig. 4 are shown some of the obtained results, considering the voltage and the current in the power grid with different values of $\alpha$ in order to adjust the reactive power. As shown in this figure, the simulations were performed in eight different modes of operation in order to analyze the behavior of the power converter with unitary power factor, with inductive power factor, and with capacitive power factor. In the simulation model was considered the model of the bidirectional power converter, an electrical model of batteries, and a digital controller (programmed in C language).

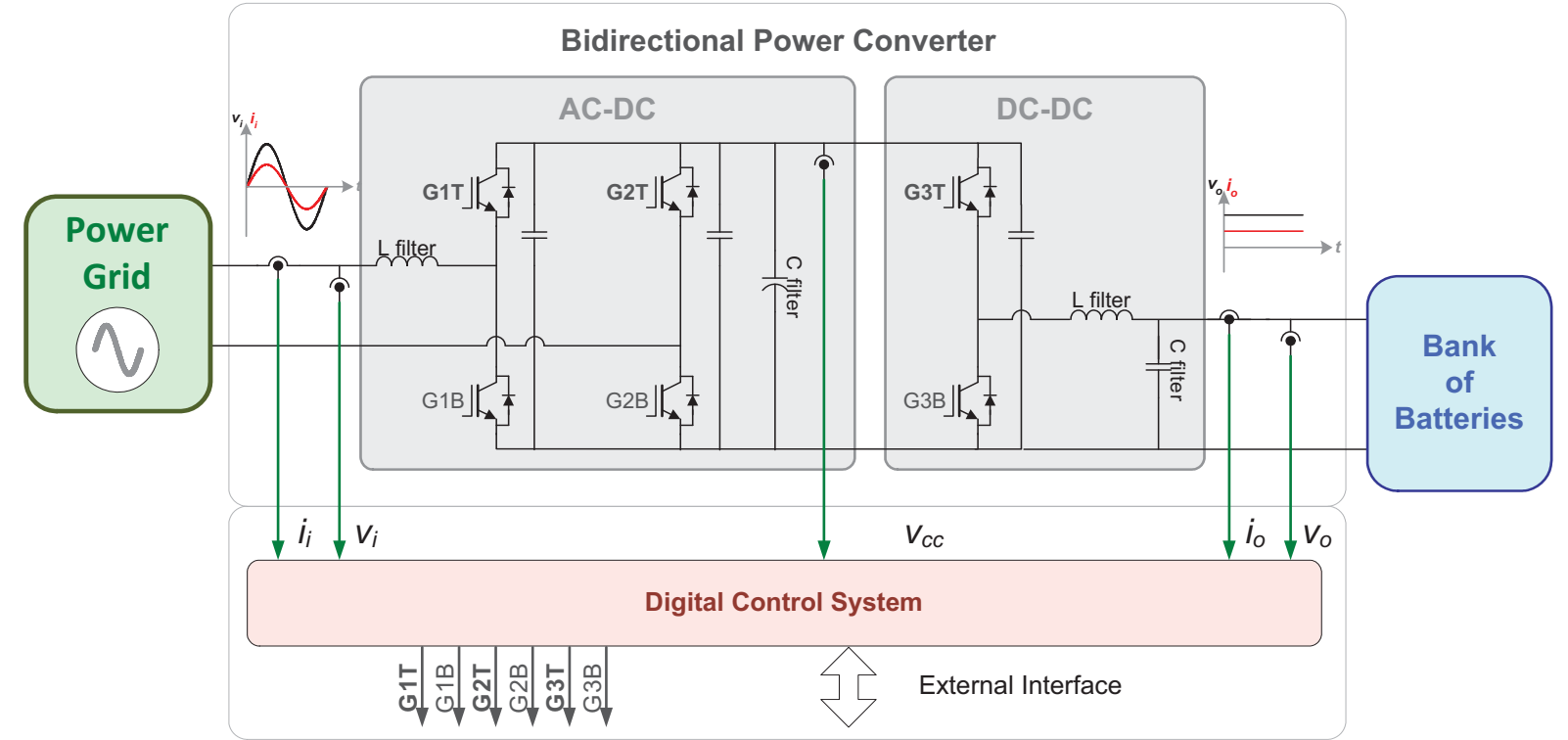

Fig. 2. Schematic of the presented bidirectional power converter. 


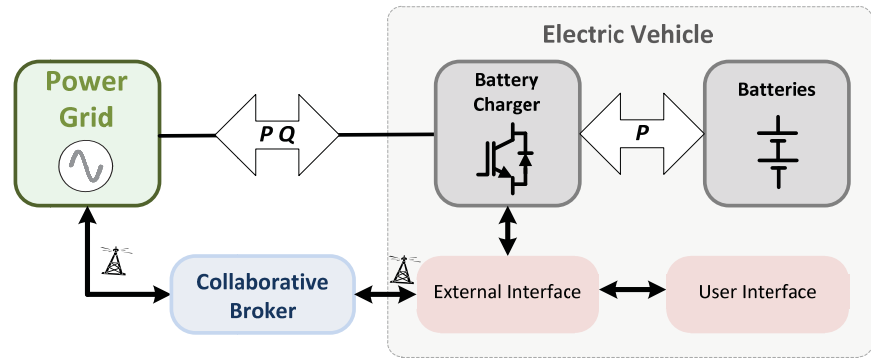

Fig. 3. Interface between the power grid and an Electric Vehicle with the possible flow of active and reactive power.

TABLE I

DIFFERENT PROFILES OF POWER CONSUMPTION

\begin{tabular}{|c|c|c|c|c|}
\hline $\begin{array}{c}\text { Power Factor } \\
\cos (\boldsymbol{\alpha})\end{array}$ & $\begin{array}{c}\text { Active } \\
\text { Power }(\boldsymbol{P})\end{array}$ & $\begin{array}{c}\text { Reactive } \\
\text { Power }(\boldsymbol{Q})\end{array}$ & $\begin{array}{c}\text { Power } \\
\text { Factor }\end{array}$ & Figure \\
\hline$\alpha=0^{\circ}$ & positive & zero & - & Fig. 4 (a) \\
\hline$\alpha=180^{\circ}$ & negative & zero & - & Fig. 4 (b) \\
\hline$\alpha=90^{\circ}$ & zero & positive & capacitive & Fig. 4 (c) \\
\hline$\alpha=-90^{\circ}$ & zero & negative & inductive & Fig. 4 (d) \\
\hline $0^{\circ}<\alpha<90^{\circ}$ & positive & positive & capacitive & Fig. 4 (e) \\
\hline $90^{\circ}<\alpha<180^{\circ}$ & negative & positive & capacitive & Fig. 4 (f) \\
\hline $180^{\circ}<\alpha<270^{\circ}$ & negative & negative & inductive & Fig. 4 (g) \\
\hline $270^{\circ}<\alpha<360^{\circ}$ & positive & negative & inductive & Fig. 4 (h) \\
\hline
\end{tabular}

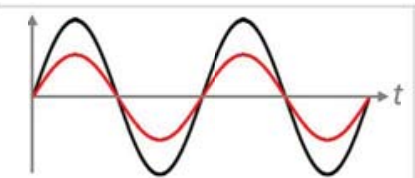

(a)

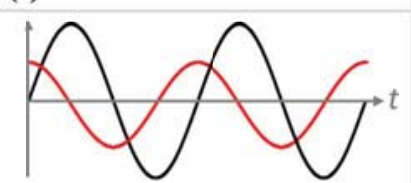

(c) $\alpha=90^{\circ}$

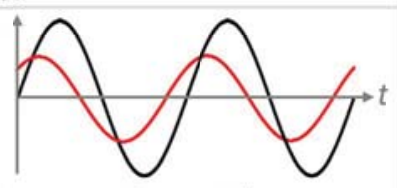

(e)

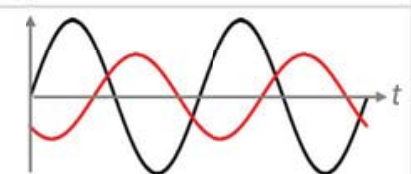

(g)

$180^{\circ}<\alpha<270^{\circ}$

$v(t)$ - Voltage (V)

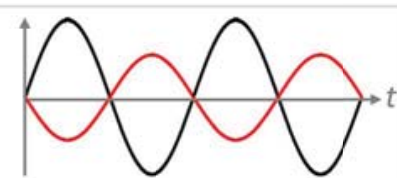

(b)

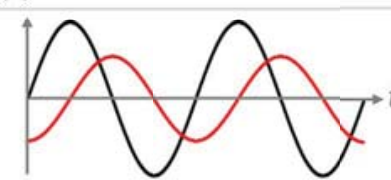

(d)

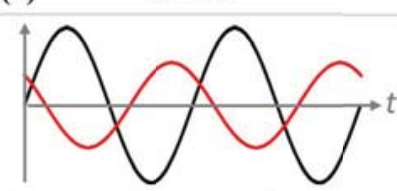

(f)

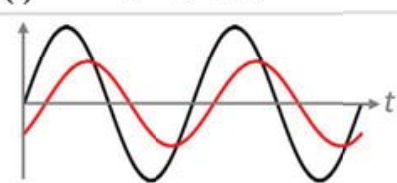

(h)

$270^{\circ}<\alpha<360^{\circ}$

$i(t)$ - Curent (A)
Fig. 4. Summary of some simulation results considering the voltage and the current in the electrical power grid with different values of $\alpha$ to adjust the reactive power.

\section{DEVElopment OF THE BATtery CHARGer} PROTOTYPE

In order to assess the operation of the presented power converter under the different modes of operation (considering the active and the reactive power control) was developed the prototype presented in Fig. 5. Thus, in this section is described in detail the bidirectional power converter and the digital control system developed. This battery charger was developed aiming to be integrated in an Electric Vehicle with Absorbed Glass Mat (AGM) batteries with nominal voltage $96 \mathrm{~V}$ and nominal capacity $33 \mathrm{Ah}$. In accordance with the manufacturer, the charging algorithm should be divided in three stages: Bulk; Absorption; and Float. The first stage consists in charging the batteries with constant current until the voltage reach $115 \mathrm{~V}$. In the second stage the voltage is maintained at $115 \mathrm{~V}$ until the current accepted by the battery falls below than $0.1 \mathrm{~A}$. Finally, in the third stage, the voltage is maintained at $108 \mathrm{~V}$ to compensate the self-discharge.

\section{A. Bidirectional Power Converter}

As referred before, the presented battery charger is composed by two bidirectional power converters, one AC-DC and the other DC-DC. To the AC-DC bidirectional power converter was used the switching technique Periodic Sampling based on the Direct Current Control (DCC). This technique does not work at fixed frequency, but it establishes a maximum frequency limit, which is $20 \mathrm{kHz}$ in this case. On the other hand, to the DC-DC converter was used the switching technique Pulse Width Modulation (PWM), which works with a fixed frequency of $20 \mathrm{kHz}$. The bidirectional flow of energy is obtained through the adequate control of the IGBTs.

\section{B. Digital Control System}

The control system, which implements the algorithms during the operation as $\mathrm{G} 2 \mathrm{~V}$ and $\mathrm{V} 2 \mathrm{G}$, is composed by several electronic circuits with analogue and digital signals. The control algorithms of the developed digital control system were implemented in a DSP TMS320F28335. The internal ADCs of the DSP receive the voltages and the currents signals that are providled by the signal conditioning circuit, and in conjunction with the external interface, generate the control signals to the command circuit. The voltage and current signals of the bidirectional power converter are obtained through hall-effect LEM sensors in the signal conditioning circuit. This circuit also provides protection against overvoltages and overcurrents in both sides of the power converters. The control signals to the drivers of the IGBTs are provided by the command circuit, which receives the control signals from the DSP and receives the error signals provided by the signal conditioning circuit. The operation of the battery charger should occur in accordance with the orders given by the collaborative broker and the user interface of the Electric Vehicle, which define when it works as $\mathrm{G} 2 \mathrm{~V}$ and $\mathrm{V} 2 \mathrm{G}$, and define the value of reactive power to be produced (without exceeding the current limits of the battery charger). 


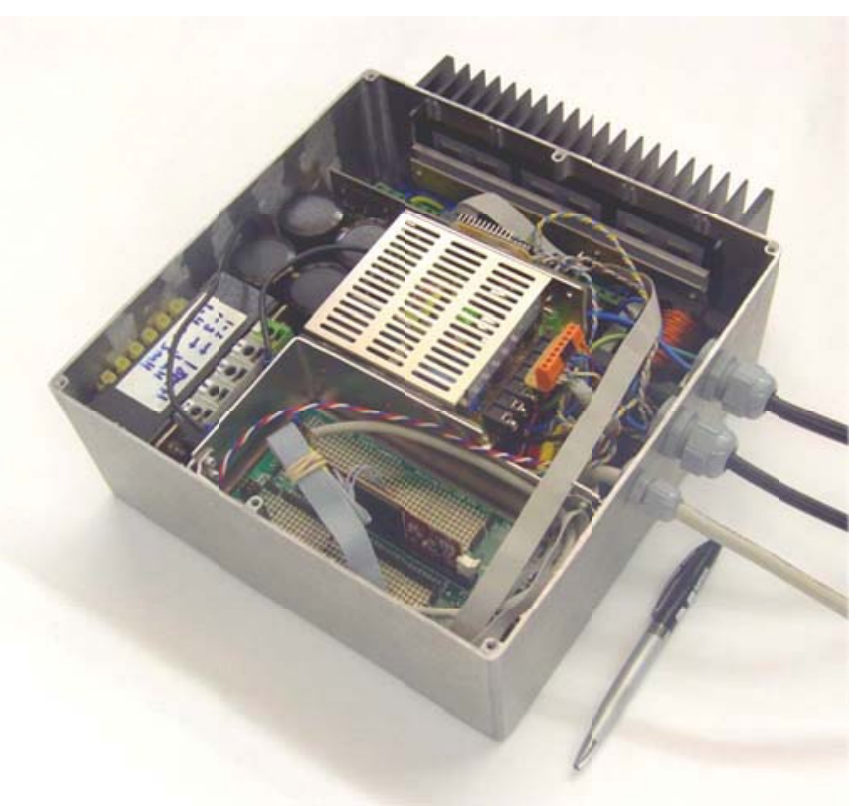

Fig. 5. Battery charger prototype developed to operate as G2V and V2G, and to control the reactive power, to be implemented in an Electric Vehicle.

\section{EXPERIMENTAL RESULTS}

In this section are presented the experimental results obtained with the developed battery charger with bidirectional power converter considering the different modes of operation presented in Tab. II. The presented results were obtained with the AGM batteries with nominal voltage $96 \mathrm{~V}$ and nominal capacity $33 \mathrm{Ah}$, and respecting the three stages of the charging (Bulk, Absorption, Float), and controlling the energy that is delivered back to the power grid (limiting the Depth-of-Discharge).

The experimental results, presented in Fig. 6, were obtained in steady state operation with a digital oscilloscope YOKOGAWA DL708E. As shown in this figure, due to other non-linear loads existing in the electrical installation, the waveform of the power grid voltage is distorted. Nevertheless, in all modes of operation the current consumed by the bidirectional power converter is sinusoidal, contributing to preserve the power quality.

TABLE II

MOdes OF Operation OF THE BidiRECTIONAL POWER CONVERTER TO OBTAIN THE EXPERIMENTAL RESULTS

\begin{tabular}{|c|c|c|c|}
\hline \multicolumn{2}{|c|}{$\begin{array}{c}\text { Power Factor } \\
\cos (\alpha)\end{array}$} & $\begin{array}{c}\text { Mode of } \\
\text { Operation }\end{array}$ & Figure \\
\hline$\alpha=0^{\circ}$ & - & G2V & Fig. 6 (a) \\
\hline$\alpha=180^{\circ}$ & - & V2G & Fig. 6 (b) \\
\hline$\alpha=45^{\circ}$ & capacitive & G2V and V2G & Fig. 6 (c) \\
\hline$\alpha=-45^{\circ}$ & inductive & G2V and V2G & Fig. 6 (d) \\
\hline
\end{tabular}
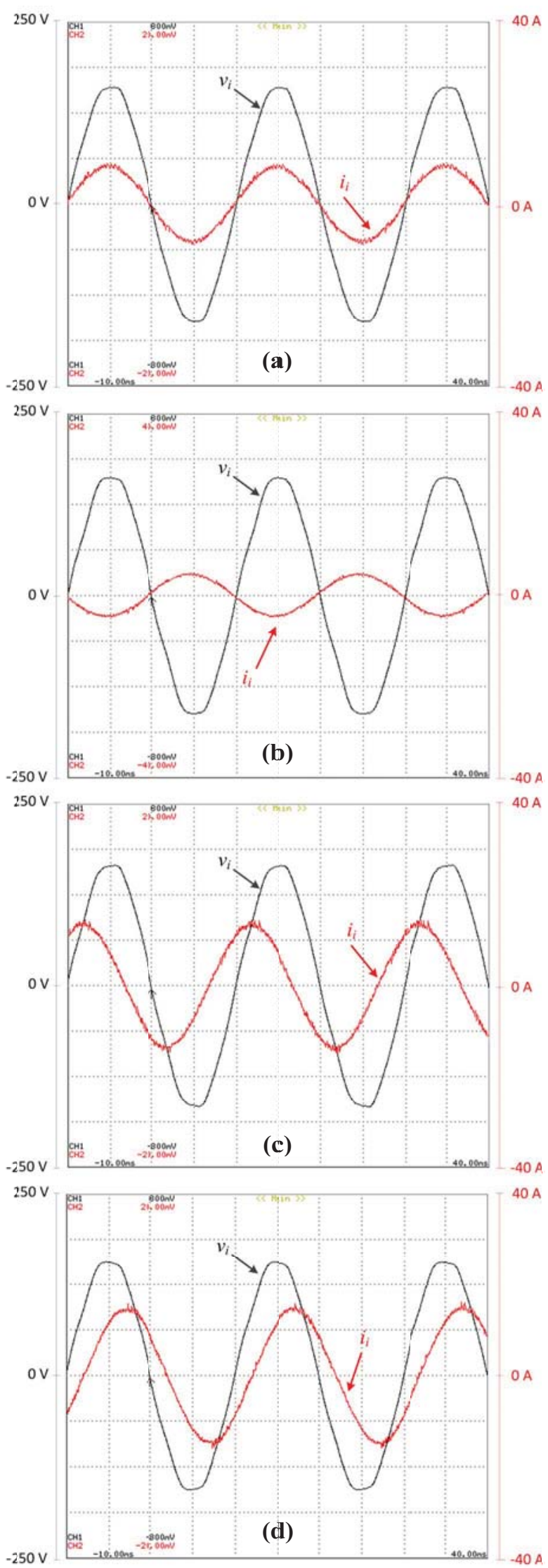

Fig. 6. Experimental results of the bidirectional power converter controlling the active and reactive power: (a) Operation with $\alpha=0^{\circ}$; (b) Operation with $\alpha=180^{\circ}$; (c) Operation with $\alpha=45^{\circ}$; and (d) Operation with $\alpha=-45^{\circ}$. 


\section{CONCLUSIONS}

In this paper was presented a battery charger for Electric Vehicles (EVs) aiming their integration in Smart Grids. This battery charger allows the interaction with the power grid to charge the batteries (Grid-to-Vehicle - G2V mode) and to deliver part of the stored energy in the batteries back to the power grid (Vehicle-to-Grid - V2G mode). Through the operation of this bidirectional battery charger the EVs can be used to regulate the reactive power and to act as local Energy Storage Systems (ESS). This way, the EVs will be able to help the power grid to regulate the active and reactive power flow, stabilizing the production and consumption of energy.

Taking into account the bidirectional power converter topology that was presented in this paper, the consumed current is sinusoidal and it is possible to regulate the power factor (to control the reactive power), aiming to contribute to mitigate power quality problems in the power grid. The reactive power control is performed considering the user interface of the Electric Vehicle, the requirements of the power grid defined by a collaborative broker, and concerning the current limits of the bidirectional power converter.

In a first stage, the behavior of the bidirectional power converter was evaluated under different scenarios through computer simulations. Then the behavior of the bidirectional power converter was evaluated with a prototype, which was developed aiming to reduce its volume and weight, in order to be integrated in an Electric Vehicle with Absorbed Glass Mat (AGM) batteries. In this paper were presented the simulations and experimental results obtained.

\section{ACKNOWLEDGMENT}

This work is financed by FEDER Funds, through the Operational Programme for Competitiveness Factors COMPETE, and by National Funds through FCT Foundation for Science and Technology of Portugal, under the projects: FCOMP-01-0124-FEDER-022674, PTDC/EEAEEL/104569/2008 and MIT-PT/EDAM-SMS/0030/2008.

\section{REFERENCES}

[1] B. Kramer, S. Chakraborty, B. Kroposki, "A review of plug-in vehicles and vehicle-to-grid capability," IEEE IECON'08 Industrial Electronics Conference, pp.2278-2283, November 2008.

[2] M. C. Kisacikoglu, B. Ozpineci, L. M. Tolbert, "Examination of a PHEV Bidirectional Charger System for V2G Reactive Power Compensation," IEEE APEC Applied Power Electronics Conference and Exposition, pp.458-465, February 2010.

[3] V. Monteiro, João C. Ferreira, J.G. Pinto, D. Pedrosa, João L. Afonso, "iV2G Charging Platform" 13th International IEEE Conference on Intelligent Transportation Systems (ITSC), pp. 409-414, MadeiraPortugal, 19-22 September, 2010.

[4] A. Y. Saber, G. K. Venayagamoorthy, "Optimization of Vehicle-toGrid Scheduling in Constrained Parking Lots," IEEE PES Power \& Energy Society General Meeting, pp.1-8, 2009.
[5] João C. Ferreira, Alberto R. Silva, V. Monteiro, João L. Afonso, "Collaborative Broker for Distributed Energy Resources", International Symposium on Computational Intelligence for Engineering Systems (ISCIES), ISEC, Coimbra-Portugal, 16-18 November, 2011.

[6] V. Monteiro, H. Gonçalves, João L. Afonso, "Impact of Electric Vehicles on Power Quality in a Smart Grid Context", 11th IEEE International Conference on Electrical Power Quality and Utilization (EPQU), Lisbon-Portugal, 17-19 October, 2011.

[7] J. C. Gomez, M. M. Morcos, "Impact of EV battery chargers on the power quality of distribution systems," IEEE Transactions on Power Delivery, vol.18, issue:3, pp.975-981, 2003.

[8] H. Wei, I. Batarseh, "Comparison Basic Converter Topologies for power factor correction," IEEE Southeastcon, pp.348-353, April 1998.

[9] Z. Yang, P. C. Sen, "Recent developments in high power factor switchmode converters," IEEE Canadian Conference on Electrical and Computer Engineering, vol.2, pp. 477-480, 1998.

[10] J. Chen, D. Maksimovic, R. Erickson, “A New Low-Stress Buck-Boost Converter for Universal-Input PFC Applications," IEEE APEC Applied Power Electronics Conference and Exposition, vol.1, pp.343-349, 2001.

[11] J. C. Salmon, "Circuit topologies for PWM boost rectifiers operated from 1-phase and 3-phase AC supplies and using either single or split DC rail voltage outputs," IEEE APEC Applied Power Electronics Conference and Exposition, vol.1, issue:0, part:1, pp.473-.479, March 1995.

[12] X. Zhou, "A comparison of converter topologies for vehicle-to-grid applications: Three-leg converter versus H-bridge converter," IEEE IECON'09 Industrial Electronics Conference, pp.3711-3716, November, 2009

[13] D. C. Erb, O. C. Onar, A. Khaligh, "Bi-directional charging topologies for plug-in hybrid electric vehicles," IEEE APEC Applied Power Electronics Conference and Exposition pp.2066-2072, 2010.

[14] S. Lisheng, A. Meintz, M. Ferdowsi, "Single-phase bidirectional ACDC converters for plug-in hybrid electric vehicle applications," IEEE VPPC Vehicle Power and Propulsion Conference, pp.1-5, 2008.

[15] J. A. P. Lopes, F. J. Soares, P. M. R. Almeida, "Integration of Electric Vehicles in the Electric Power System," Proceedings of the IEEE, Volume:99, Issue:1, pp.168-183, 2011.

[16] L. Zhao, S. Prousch, M. Hubner, A. Moser, "Simulation Methods for Assessing Electric Vehicle Impact on Distribution Grids," IEEE PES Transmission and Distribution Conference and Exposition, pp.1-7, 2010.

[17] Y. Song, X. Yang, Z. Lu, "Integration of Plug-in Hybrid and Electric Vehicles Experience from China," IEEE PES Power and Energy Society General Meeting, pp.1-6, 2010.

[18] P. Kadurek, C. Ioakimidis, P. Ferrao, "Electric Vehicles and their Impact to the Electric Grid in isolated systems," IEEE POWERENG Power Engineering, Energy and Electrical Drives, pp.49-54, 2009.

[19] C. Jin, N. Lu, S. Lu, Y. Makarov, R. A. Dougal, "Coordinated control algorithm for hybrid energy storage systems," IEEE Power and Energy Society General Meeting, pp.1-7, July 2011

[20] MAGICC - Mid-Atlantic Grid Interactive Cars Consortium, "MAGICC Brochure" [Online]. Available: http://www.magicconsortium.org

[21] R. Alves, D. Gonçalves, J.G. Pinto, J.Batista, João L. Afonso, "Development of an Electrical Power Quality Monitor Based on a PC", IECON 2009 - The 35th Annual Conference of the IEEE Industrial Electronics Society, Porto, Portugal, 35 November, 2009.

[22] João L. Afonso, Carlos Couto, Júlio Martins, "Active Filters with Control Based on the p-q Theory", IEEE Industrial Electronics Society Newsletter, vol. 47, issue:3, pp.5 10, September, 2000.

[23] J. G. Pinto, P. Neves, D. Gonçalves, João L. Afonso, "Field results on developed three-phase four-wire Shunt Active Power Filters," IEEE IECON'09 Industrial Electronics Conference, pp.480-485, November 2009.

[24] C. Camus, C. M. Silva, T. L. Farias, J. Esteves, "Impact of Plug-in Hybrid Electric Vehicles in the Portuguese Electric Utility System," IEEE POWERENG International Conference on Power Engineering, Energy and Electrical Drives, pp.285-290, 2009. 